MATEC Web of Conferences 21, 10003 (2015)

DOI: $10.1051 /$ matecconf $/ 20152110003$

(C) Owned by the authors, published by EDP Sciences, 2015

\title{
Fabrication of NiTi shape memory alloy by Micro-FAST
}

\author{
Kunlan Huang, Yi Qina , Jie Zhao, Muhammad Bin Zulkipli, and Hasan Hijji \\ Centre for Micro-Manufacturing, Dept. of DMEM, University of Strathclyde, James Weir Building, \\ 75 Montrose Street, Glasgow G1 1XQ, UK
}

\begin{abstract}
A NiTi shape memory alloy, known as nitinol, has been intensively studied for last five decades. The NiTi alloy with large size is commonly produced by vacuum sintering, thermal explosion mode of self-propagating high-temperature synthesis (TESHS) and spark plasma sintering (SPS). These methods are, however, rarely utilized for the forming of miniature and micro-sized components and have their own limits and disadvantages, such as long process chains and low efficiency with the processes. In the study reported in this paper, an innovation in rapid powder consolidation technology, called Micro-FAST (combining micro-forming and electric-current activated sintering techniques (FAST)) is introduced for the forming of micro-components in which the loose powders are loaded directly into the die, followed by electric-sintering. In the study, $\Phi 4.0 \mathrm{~mm} \times 4.0 \mathrm{~mm}$ miniature cylinders were formed with pre-alloyed NiTi powders. Sintered sample with relative density of $98.65 \%$ has been fabricated at a sintering temperature of $1150{ }^{\circ} \mathrm{C}$ in a relatively short cycle time $(119.5 \mathrm{~s})$. Based on the results of SEM and XRD, it was found that the densified samples with $\mathrm{Ni}_{3} \mathrm{Ti}$, NiTi and $\mathrm{NiTi}_{2}$ phases were produced.
\end{abstract}

\section{Introduction}

Nickel-titanium alloy near the equiatomic concentration is well known for its shape memory effect (SME) [1], and also its unique physical and mechanical properties, such as good ductility at room temperature, good vibration damping properties and corrosion properties in sea water [2].

Recently, either the element mixtures of nickel and titanium powders or pre-alloyed NiTi powders was chosen to be consolidated using powder metallurgy (P/M) process to obtain bulk material with metastable or refined state. As shown in Table 1, M.M. Verdian et al. [3] investigate the microstructure and corrosion behaviour of NiTi-Ti2Ni-Ni3Ti multiphase materials of NiTi alloy which is produced by vacuum sintering method, the NiTi powder were sintered at $1300^{\circ} \mathrm{C}$ for 2 hrs to obtain NiTi alloy with dense structure. Jaroslav ČAPEK et al. [4] prepared the NiTi samples by the thermal explosion mode of self-propagating high- temperature synthesis (TE-SHS). $\Phi 10 \mathrm{~mm} \times 30 \mathrm{~mm}$ sized samples were formed at a lower sintering temperature $\left(1100^{\circ} \mathrm{C}\right)$ for about 25 mints comparing with the traditional vacuum sintering method. L.L. Ye et al. [5] consolidated the elemental nickel and titanium powder mixture

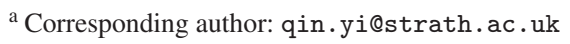

This is an Open Access article distributed under the terms of the Creative Commons Attribution License 4.0, which permits unrestricted use, distribution, and reproduction in any medium, provided the original work is properly cited. 


\section{MATEC Web of Conferences}

Table 1. The sintering temperature corresponding to the samples formed.

\begin{tabular}{|c|c|c|c|}
\hline $\begin{array}{c}\text { Forming } \\
\text { method }\end{array}$ & Raw material & $\begin{array}{c}\text { Sintering } \\
\text { temperature }\left({ }^{\circ} \mathrm{C}\right)\end{array}$ & $\begin{array}{c}\text { Sintering } \\
\text { cycle time }\end{array}$ \\
\hline Vacuum sintering [3] & Pre alloyed NiTi powder & 1300 & 2 hours \\
\hline TE-SHS [4] & Mixed Ni powder and Ti powder & 1100 & 25 mints \\
\hline SPS [5] & Mixed Ni powder and Ti powder & 1100 & $10 \sim 15$ mints \\
\hline
\end{tabular}



Figure 1. Illustration of the Micro-FAST sintering and forming process.

using Spark plasma sintering (SPS) method, which is an effective method to fabricate the NiTi alloy and further shorten the sintering cycle time to $10 \sim 15$ mints.

As TiNi alloy is widely applied and demands on miniature/micro-metal-products increase significantly, a new rapid powder consolidation technology, called Micro-FAST (combining microforming and electric-current activated sintering techniques (FAST)) was proposed by authors [6] for the forming of micro-components for various material systems such as metals, ceramics and composites, the process being illustrated in Fig. 1. The advantages of this technique over conventional ones include lower sintering temperature, shorter forming time, and marked improvements in sintering density. In MicroFAST, the powders are formed/sintered under simultaneous influences of the current, high temperature and forming-pressure. Loose powders are placed directly into a small die, the heating is effected by passing an AC current through the die to generate the necessary temperature in the powders, and a pressure is applied onto the powders simultaneously. The whole forming process only took only about 4 minutes. Direct manufacture from powders and no additional binders added to the powders indicate an energy conserving and environmentally friendly forming process. In the present work, the pre-alloyed NiTi powders were rapidly consolidated by Micro-FAST to obtain miniature bulk samples.

\section{Experiment}

Pre-alloyed NiTi powders (99\% purity) with an average particle size of $36 \mu \mathrm{m}$ were used for experiments. The nominal composition of the powders was $\mathrm{Ni}-55.87 \%$ and $\mathrm{Ti}-44.13 \%$. The powder was supplied by MBN Nanomaterialia, Italy. A scanning electron micrograph of the initial powder is shown in Fig. 2.

Figure 3 shows the schematic of the tool-set used in the experiments with a Gleeble- 3800 thermal simulation machine from Dynamic System Inc., USA. The machine controls the heating process with a computer-controlled system which is able to preset a value of the heating rate, and the accuracy of the temperature control is within $\pm 3{ }^{\circ} \mathrm{C}$. The electric field produced by the machine has low voltage and high current $(3 \sim 10$ Volts and $3000 \sim 30000 \mathrm{~A})$. The as-received powders consisted of agglomerates which are sufficient to make up a sample with the size of $\Phi 4.0 \mathrm{~mm} \times 4.0 \mathrm{~mm}$ (solid cylinder). After 


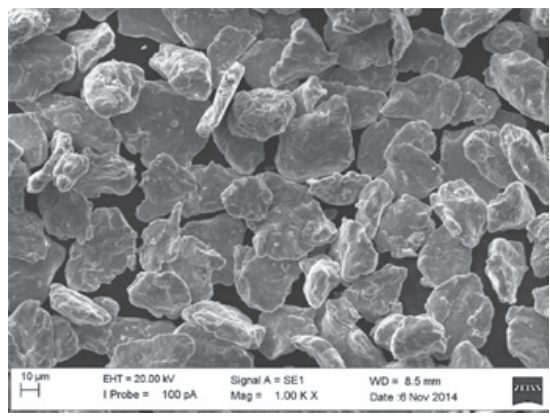

Figure 2. SEM micrographs of NiTi powders.



Figure 3. Tool set used and experiment setup with Gleeble-3800.

Table 2. The sintering temperature corresponding to the samples formed.

\begin{tabular}{|l|l|l|l|}
\hline Specimen designation & Sintering temperature $\left({ }^{\circ} \mathrm{C}\right)$ & Sintering cycle time $(\mathrm{s})$ & Relative density $(\%)$ \\
\hline $1 \#$ & 950 & 105.5 & 94.59 \\
\hline $2 \#$ & 1050 & 112.5 & 96.32 \\
\hline $3 \#$ & 1150 & 119.5 & 98.65 \\
\hline
\end{tabular}

weighting, the powder was filled into a die. The die model is shown in Fig. 3. The die filled with $316 \mathrm{~L}$ stainless steel powders was then placed onto the Gleeble-3800 machine, and it was then heated rapidly to a certain sintering temperature at a preset heating rate in a vacuum $(<10-4 \mathrm{~Pa})$ (a high electric current passes through the die-set), and at the same time, a preset pressure was applied onto the punch and die-bottom-side. The sintering temperature and sintering cycle time (including the cooling period) of the experiment are shown in Table 2.

The sintered compact's relative density was measured by the electronic analytical balance TP- 214 . The pore size distributions were observed under a scanning electron microscope JSM-5900LV, JEOL (Japan).

\section{Results and discussion}

\subsection{The apparent morphology of formed samples}

The results selected from the experiments can be found in Table 2. The formed samples show high relative density $(94.59 \%$ to $98.65 \%)$. That means NiTi powders can be well sintered to miniature 


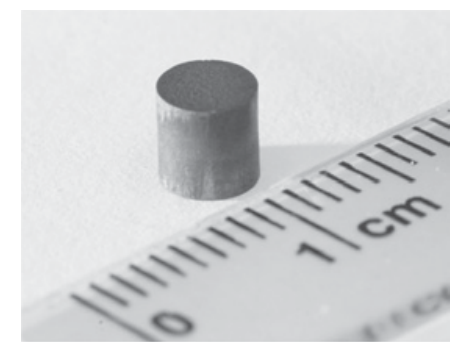

Figure 4. A formed sample (solid cylinder) with a size of $\Phi 4.0 \mathrm{~mm} \times 4.0 \mathrm{~mm}$.

compacts under the coupled actions from multi-fields within relatively short sintering time (e.g., $<2$ mints). It shows that dependence of the relative density onto the sintering temperature is strong and a tendency towards an increase in relative density. The morphology of a formed sample can be seen from Fig. 4. The cylinder samples were designed to have a dimension $\Phi 4.0 \mathrm{~mm} \times 4.0 \mathrm{~mm}$, and the samples formed were found to have similar dimensions.

\subsection{Microstructure of the raw powder and formed sample}

The excellent performance of NiTi alloys in corrosive environments has been described in the literature [7]. Three stable intermetallic phase $\left(\mathrm{Ti}_{2} \mathrm{Ni}, \mathrm{NiTi}\right.$ and $\left.\mathrm{Ni}_{3} \mathrm{Ti}\right)$ can be formed during consolidation of NiTi alloy. The formation of secondary phases such as $\mathrm{Ti}_{2} \mathrm{Ni}$ and $\mathrm{Ni}_{3} \mathrm{Ti}$ is unfavorable for the shape memory properties of NiTi alloy. However, G. Chen et al. [8] investigated that it is possible to develop a novel type of wear and corrosion resistant material employing a NiTi alloy reinforced by hard $\mathrm{Ti}_{2} \mathrm{Ni}$ and $\mathrm{Ni}_{3} \mathrm{Ti}$ phases. Therefore, $\mathrm{NiTi}-\mathrm{Ti}_{2} \mathrm{Ni}_{-} \mathrm{Ni}_{3} \mathrm{Ti}$ multiphase intermetallics can be considered as new corrosion and wear resistant materials for a wide range of industrial applications [3].

\subsubsection{Microstructure of the raw powder}

As shown in Fig. 5(a), after thermal treatment of initial pre-alloyed NiTi powders, precipitation of different phases occurs as shown by SEM images. The light grey regions represent Ni-rich phase, the grey region represent NiTi phase and the dark grey represent Ti-rich phase. XRD spectra with an enlargement between $40^{\circ}$ and $60^{\circ} 2 \theta$ is shown in Fig. 5(b). After the thermal treatment, $\mathrm{NiTi}$ and $\mathrm{Ni}_{2} \mathrm{Ti}$ are the main phases present. $\mathrm{Ni}_{3} \mathrm{Ti}$ and $\mathrm{Ni}$ patterns are also present.

\subsubsection{Microstructure of the formed sample}

From the micrographs of the formed sample 3\# shown in Fig. 6 and comparing the micrographs of the initial formed samples shown in Fig. 5, the following were found:

(1) The sintered sample $3 \#$ had porosity less than $2 \%$. The porosity content and size (less than $500 \mathrm{~nm}$ ) is low for NiTi alloy produced by the traditional sintering methods. In the case of sintered parts, the inherent porous nature of the material provides a narrow tortuous electrolyte path that promotes corrosion propagation. Therefore, denser and less porous components are preferred while corrosion is the main concern [9].

(2) The densified sample can be fabricated at a lower temperature of $1150{ }^{\circ} \mathrm{C}$ within a short sintering cycle time $(119.5 \mathrm{~s})$ under the effect of multi-physical fields, especially the electric field (low voltage: $3 \sim 10$ Volts and high current: $3000 \sim 30000 \mathrm{~A}$ ). In density of sample after pressureless 

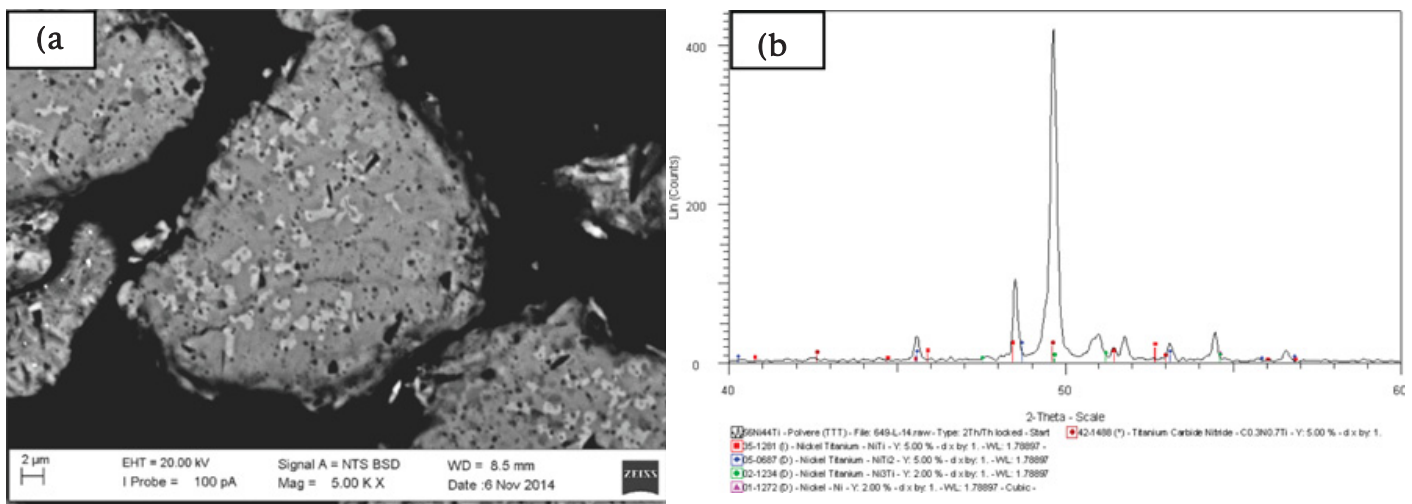

Figure 5. SEM micrograph (a) and XRD result (b) of the NiTi powders.
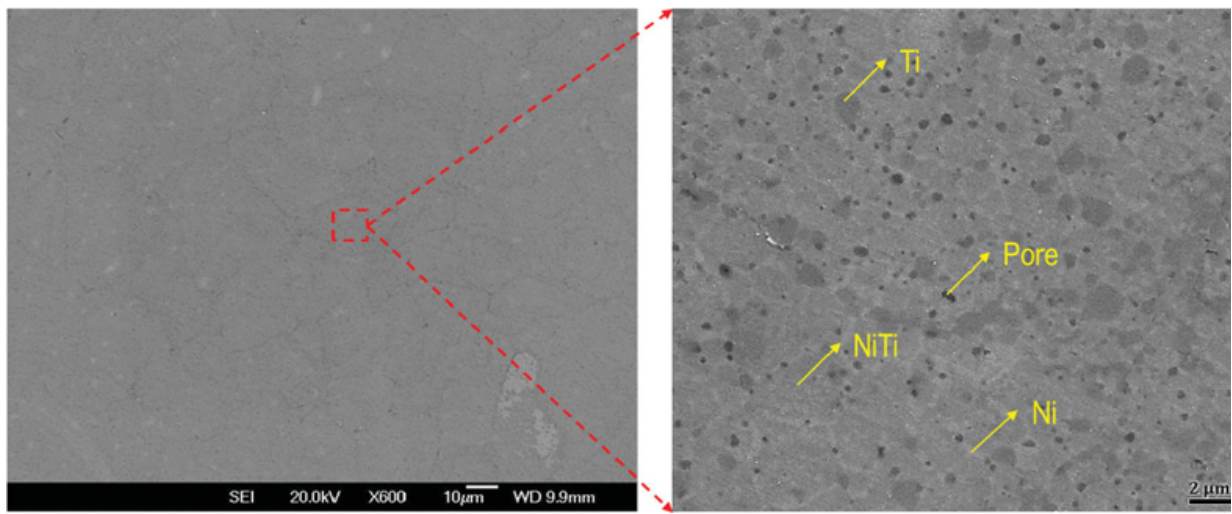

Figure 6. SEM micrograph of the formed sample 3\#: sintered at $1150^{\circ} \mathrm{C}$, sintering cycle time is $119.5 \mathrm{~s}$.

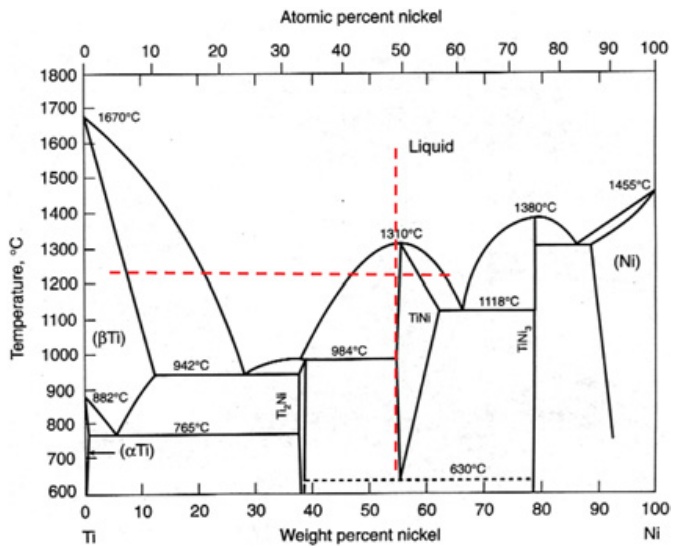

Figure 7. Ni-Ti phase diagram [3]. 


\section{MATEC Web of Conferences}

sintering depends on the sintering temperature. Densities up to $95 \%$ can be achieved for sintering temperature near the melting point of the alloy. As shown in Ni-Ti phase diagram (see Fig. 7), the melting point of the NiTi phase is about $1310^{\circ} \mathrm{C}$. Thus, as pre-alloyed NiTi powders were sintered at $1250{ }^{\circ} \mathrm{C}$ to minimize porosity [10]. The sheets with a porosity of $15 \%$ were obtained by sintering of wet sprayed pre-alloyed NiTi powders at $1230^{\circ} \mathrm{C}$ [3]. In SPS, the sintering temperature of NiTi was lower than $1200^{\circ} \mathrm{C}$. However, as the pulse is very short $(\sim 2 \mathrm{~s})$ the generated heat is not enough to really effect sintering, a further dwell sintering time ( $>5$ minutes) appears to be necessary on account of the presence of the neck generated by volume diffusion [11].

(3) As shown in Fig. 6 (right), the microstructure of sintered sample also showed a multi-phase structure in which the Ti-rich phase and NiTi phase are embedded in the Ni-rich phase, which is similar with the microstructure of initial powder. On the other hand, from the Ni-Ti phase diagram which is shown in Fig. 7, it can be found that the melting points of $\mathrm{Ni}_{3} \mathrm{Ti}, \mathrm{NiTi}$ and $\mathrm{Ti}_{2} \mathrm{Ni}$ are about 1380, 1310 and $984{ }^{\circ} \mathrm{C}$, respectively. Therefore, during the sintering process, NiTi can be partially melted. In addition, a liquid phase can be generated due to present of low-melting point $\mathrm{Ti}_{2} \mathrm{Ni}$ component. The presence of liquid phase decreases the porosity content of sample. During cooling period, a eutectic reaction occurs and the liquid phase is transformed into NiTi and $\mathrm{Ni}_{3} \mathrm{Ti}$ at $1180^{\circ} \mathrm{C}\left(\mathrm{L} \rightarrow \mathrm{NiTi}+\mathrm{Ni}_{3} \mathrm{Ti}\right)$. Therefore, $\mathrm{NiTi}$ can be formed again. At $984^{\circ} \mathrm{C}, \mathrm{Ti}_{2} \mathrm{Ni}$ can be formed through the peritectic reaction: $\mathrm{L}+\mathrm{NiTi} \rightarrow \mathrm{Ti}_{2} \mathrm{Ni}[3]$.

\section{Conclusions}

From the work completed in this study the following conclusions can be drawn:

(1) Compared with conventional sintering methods, the Micro-FAST micro-manufacturing technology is an efficient process, and it has lower energy consumption and little impact to the environment due to directly forming the component from loose powders.

(2) Miniature components with NiTi powders can be made using this micro-forming method. The density of the sample miniature components made from NiTi powders can reach over $98.65 \%$ when they were sintered at a relatively low sintering temperature $\left(1150^{\circ} \mathrm{C}\right)$, short sintering cycle time (119.5 s).

(3) The study on the characteristics of the micrograph of the initial pre-alloyed NiTi powders and the formed sample suggest that $\mathrm{NiTi}-\mathrm{Ti}_{2} \mathrm{Ni}-\mathrm{Ni}_{3} \mathrm{Ti}$ multiphase intermetallics can be produced under the coupled multi-fields activations. Deformation and breakage of particles are two critical mechanisms that help to achieve densification. The presence of $\mathrm{Ti}_{2} \mathrm{Ni}$ liquid phase decreases the porosity content of sample.

(4) In the future work, the analysis of shape memory properties and corrosion resistance experiment of formed NiTi alloy should be conducted.

The authors would like to acknowledge the funding support from European Commission through FP7 FOF MicroFAST Project (GA No. 608720)). The authors would specially thank Prof. Jianguo Lin and his colleagues in Imperial College London for providing the Gleeble machine for conducting the experiment and for their kind support through the experiment. Thank Micro-FAST project partners for supplying the powder materials for the experiments as well.

\section{References}

[1] D.S. Li, X.P. Zhang, Z.P. Xiong, Y.-W. Mai, J. Alloys Compd. 490 (2010)

[2] D. Cluff, S.F. Corbin, Intermetallics 18 (2010)

[3] M.M. Verdian, K. Raeissi, M. Salehi, S. Sabooni, Vacuum 86 (2011) 


\section{ICNFT 2015}

[4] J.Č. Apek, V. Kučera, M.F. Ousová, D. V Ojtěch, in:, Met. 2013 (2013)

[5] L.Ye, Z. Liu, K. Raviprasad, M. Quan, M. Umemoto, Z. Hu, Mater. Sci. Eng. A 241 (1998)

[6] K. Huang, Y. Yang, Y. Qin, G. Yang, D. Yin, Scr. Mater. 99 (2015)

[7] S.F. Corbin, D. Cluff, J. Alloys Compd. 487 (2009)

[8] G. Chen, K.D. Liss, P. Cao, Acta Mater. 67 (2014)

[9] A.S. Jabur, J.T. Al-Haidary, E.S. Al-Hasani, J. Alloys Compd. 578 (2013)

[10] J. Mentz, M. Bram, H.P. Buchkremer, D. Stöver, Mater. Sci. Eng. A 481-482 (2008)

[11] D.M. Hulbert, A. Anders, J. Andersson, E.J. Lavernia, A.K. Mukherjee, Scr. Mater. 60 (2009) 